\title{
INCIDENCE OF PERSISTENCE NASAL OBSTRUCTION AFTER ADENOIDECTOMY: A THREE YEARS EXPERIENCE AND PERCEPTION.
}

\author{
Delwar AHM', Hossain ABMT², Mazumder $\mathrm{JA}^{3}$, Mustafa $\mathrm{MG}^{4}$. \\ ${ }^{1}$ Dr A H M Delwar, Associate Professor of Otorhinolaryngology, Cumilla Medical College, Bangladesh. \\ ${ }^{2}$ Dr ABM Tofazzal Hossain, Associate Professor of ORL-HNS, Faculty of Medicine and Health Sciences University of Sabah, \\ 88400 Kota kinabalu, Malaysia. \\ ${ }^{3}$ Dr Jahangir Alam Mazumder, Associate Professor of Otolrhinoaryngology, Cumilla Medical College, Bangladesh. \\ ${ }^{4}$ Dr Md Golam Mustafa, Associate Professor of Otolrhinoaryngology, Cumilla Medical College, Bangladesh.
}

Address in Correspondence:

Dr A H M Delwar, Associate Professor of Otorhinolaryngoloy, Cumilla Medical College, Cumilla, Post code-3500, Bangladesh. Email: mamun.delwar196@gmail.com

Mobile: +8801711246978 .

DOI: $10.31364 / \mathrm{SCIRJ} / \mathrm{v} 8 . \mathrm{i} 3.2020 . \mathrm{P} 0320751$

http://dx.doi.org/10.31364/SCIRJ/v8.i3.2020.P0320751

\begin{abstract}
:
Background:

Santorini and Wilhelm Meyer both were described the Adenoids(ADs) or Nasopharyngeal Tonsil in the $17^{\text {th }}$ and $18^{\text {th }}$ century as "Luskha's Tonsil" or "Nasopharyngeal Vegetations" which is the part of waldeyer's ring of lymphoid tissue at the portal of the respiratory system. Enlarged adenoid or Adenoids(ADS) compromise the natural pathway of breathing causes obligate mouth breathing and is developed Adenoids Facies. As a result the moulding action of tongue on the hard palate is lost. The concavity of the hard palate is increasing upwards and pressing over the nasal septal constituents. Due to delayed treatment, as a craniofacial development is progressing, the pressure is increasing over the septum and the septum is incurring and deviated to one side. As a consequence hypertrophy inferior turbinate also occur. After adenoidectomy some children continue to suffer nasal obstruction. The aim of our study is to find out the relative incidence and frequency of those children who were suffering from nasal obstruction after adenoidectomy and their management.
\end{abstract}

Method:

It was a cohort retrospective study of 67 children who were performed adenoidectomy or adenotonsillectomy in the department of Otorhinolaryngology and Head-Neck surgery, cumilla medical college, Bangladesh from 01-07-2016 to 31-06-2019. All 67 patients were performed adenoidectomy and postoperative follow up X-ray nasopharynx lateral view was done to see the relapsing of adenoid tissue. Relapsing cases were excluded from the study.

Results:

Incidence of persistence nasal obstruction was $0.06 \%$ out of total outdoor patient, $2.44 \%$ in total indoor operation and $20.87 \%$ in total adenoidectomy patient. After 6 months follow up 20.87\% (67/321) children were suffering from persisting nasal obstruction. Of them 
$59(88.05 \%)$ children were treated medically and $8(11.95 \%)$ were treated surgically, $3(4.88 \%)$ by septoplasty, $3(4.88 \%)$ by cauterization and 2(2.99\%) by FESS.

Conclusion:

After adenoidectomy of children the parents appeal to complete cure of their children from the disease. So some parent should be counseling for the probable outcome of their children who were suffering from Allergic Rhinitis, DNS and HIT with adenoids and persistence of nasal obstruction after adenoidectomy and motivational work should be done before first operation that these children may be needed medical treatment and repeated surgery afterwards.

Key Words: Enlarged adenoid or adenoids(ADS), Deviated Nasal Septum(DNS), Hypertrophic Inferior Turbinate(HIT), CT(Computed Tomography), FESS(Functional Endoscopic Sinus Surgery), MRI(Magnetic Resonance Imaging).

Introduction:

Adenoid is a lymphoid tissue in the posterior wall and roof of the nasopharynx just behind the posterior end of nasal orifice or choana which is developed 4-6 weeks of gestation and 18\% children adenoid are identified by MRI(Magnetic Resonance Imaging) at the age of four months. ${ }^{1}$ From five months it grows rapidly, most enlargement of adenoid is seen in 7 years and after 15 years it regresses. ${ }^{2}$ As a part of waldeyer's ring of lymphoid tissue, the adenoid helps to develop the immunological memory of early infancy and childhood. ${ }^{3}$ There is some evidence that early adenoidectomy is may be immunologically abominable. ${ }^{4}$ But 4-10 years adenoidectomy or adenoidectomy patient shows nothing immunologically deficiency. ${ }^{5}$ Santorini and Wilhelm Meyer both were described the ADS or nasopharyngeal tonsil in the $17^{\text {th }}$ and $18^{\text {th }}$ century as 'Luskha's Tonsil' or "Nasopharyngeal Vegetation". As a consequence of ADS, the child developed chronic nasal obstruction and obligate mouth breathing leads to typical face called Adenoid Facies characterized by elongated face with dull expression, an incompetent lip seal, prominent upper incisor teeth, narrow upper dental arch, a steep mandibular plane angle and retrognathic mandible. ${ }^{6}$ Due to high arched palate, the welding action of tongue on palate is lost. The tongue position in the oral cavity is low. This leads to lower mandibular position and extended head posture leading to all craniofacial abnormalities. ${ }^{7}$ Due to concession of natural nasal airway and obligate mouth breathing the midface which included the cheek bone, nasal bones and bone supporting the face fail to progress normal rate with other parts. The outcome of this frailty of development of jaw and midface causes direct upshot on nasal septum. After adenoid surgery the establishment of the nasal airway hasten the growth of mandible but maxillary plane angle is impeded. ${ }^{8}$ Delayed treatment of adenoid, progressing craniofacial mal development and presence of high arched palate on septal constituents, the septum is incurring and deviated to one side and HIT occur in opposite side. There were insufficient study of post adenoidectomy children with septal deviation due to unequal craniofacial expansion in children. ${ }^{9}$ This is our incompetent thinking that we give more focus on adenoids but the causes like allergy or after effect of ADS related septal deviation after adenoidectomy also the matter of continuing the mouth breathing and nasal blockage. ${ }^{10}$ So mindset to the wide knowledge about HIT due to ADS, allergy or DNS and also septal deviation due to ADS which should not be breakthrough the symptom of ADS after adenoidectomy and therefore repeated surgery to correct the second or third disease entity should be the convenient approach to the parents and attended to understand the situation. ${ }^{11}$

Methods and Materials:

It is a cohort retrospective study of 67 children in the department of Otorhinolaryngology and Head-Neck surgery, Cumilla Medical College, Bangladesh from 01-07-2016 to 31-06-2019. During these three years period total 1,16,128 patient were attending in the outdoor for the treatment of various types of disease condition and total 2,738 routine operation were performed in inpatient department. Amongst this surgery adenoidectomy were 321. Incidence of study case amid these three groups were calculated. All 67 were post adenoidectomy children who were suffering from persistence symptoms for which they were operated. X-ray nasopharynx lateral view was done to see the existence of any adenoid tissue or relapsing of any adenoid tissue which may cause the continuity of the symptoms of the disease conditions. Relapsing cases were excluded from the study. We were follow up the children weekly for first month and monthly for next five months and after that we were decided to carry out the second surgical intervention. The other investigations were included for refractory rhinitis and existence of ADS related symptom. Blood tests were included Complete blood count and immunoglobulin study. Radiological investigations were included X-ray nose and paranasal sinuses for all cases see any other pathology in nose and paranasal sinuses. Two cases were found maxillary sinusitis and polypoidal changes of antral mucosa. CT scan of nose and paranasal sinuses were done for these two children to decide the treatment option. 
Results:

During these three years periods incidence of the post adenoidectomy children who were suffering from existence of ADS symptoms out of 1,16,128 outdoor patients were $67(0.06 \%)$. Table-1 Out of routine inpatient operative 2738 patients children were $2.44 \%$. Table2 During that time routine 321 adenoidectomy operations were done in which study cases were $20.87 \%$. Table-3 Age of the children was divided into three categories depending on their age. Out of these 67 children 0-5 years were 5(7.46\%), 5-10 years were $27(40.30 \%)$ and 10-15 years were 35(52.24\%). chart-1 The mean age was 10.46 years whereas lowest one was 5 and highest one was 15 years. Gender distribution were exhibit male were 41(61.19\%) and female were 26(38.81\%).chart-2 The persistence symptoms of ADS after adenoidectomy children were presented with various types of mild to severe symptoms which were refractory rhinitis, nasal discharge, nasal congestion, nasal blockage and mouth breathing. The first group of children presented with refractory rhinitis with nasal discharge during seasonal variations was $46(68.66 \%)$. The second group presented with refractory rhinitis, nasal discharge and nasal congestion during seasonal variations was 13(19.40\%). The third group of patient presented with refractory rhinitis, nasal discharge, nasal blockage and mouth breathing was 8(11.94\%) without any relation with seasonal variations.Chart-3 The all 67 children had a history of atopy and allergic rhinitis. The third group had a family history atopy and allergic rhinitis. After six months medical treatment first and second group of patient 59(88.05\%) seems to be normal whereas third group of patient $8(11.95 \%)$ weren't responding to medical treatment at all. They were treated by repeated surgical procedure, $3(4.48 \%)$ were treated by septoplasty, $3(4.48 \%)$ were treated by surface cauterization of HIT and rest of $2(2.99 \%)$ were treated by FESS. Table- 4

Table-1

$\mathrm{N}-1,16,128$.

Incidence of Study cases of children in outpatient department:

\begin{tabular}{|l|l|l|l|}
\hline Serial Number & Study Group & Result & Percentage \\
\hline 1 & Total Outdoor Patient & $1,16,128$ & \\
\hline 2 & Total Children Patient & 67 & $0.06 \%$ \\
\hline
\end{tabular}

Table-2

N-2738.

Incidence of Study group of Children in Routine operative inpatient department:

\begin{tabular}{|l|l|l|l|}
\hline Serial Number & Study Group & Result & Percentage \\
\hline 1 & Total Operation Executed & 2738 & \\
\hline 2 & Total Children Patient & 67 & $2.44 \%$ \\
\hline
\end{tabular}

Table-3

N-321

Incidence of study group of patient in total Adenoidectomy patient:

\begin{tabular}{|l|l|l|l|}
\hline Serial Number & Study Group & Result & Percentage \\
\hline 1 & Total adenoidectomy patient & 321 & \\
\hline 2 & Total children patient & 67 & $20.87 \%$ \\
\hline
\end{tabular}




\section{CHART-1}

Age distribution in three categories ( N-67;0-5years-5[7.46\%]:5-10years-27[40.30\%]:10-15years-35[ 52.24\%])

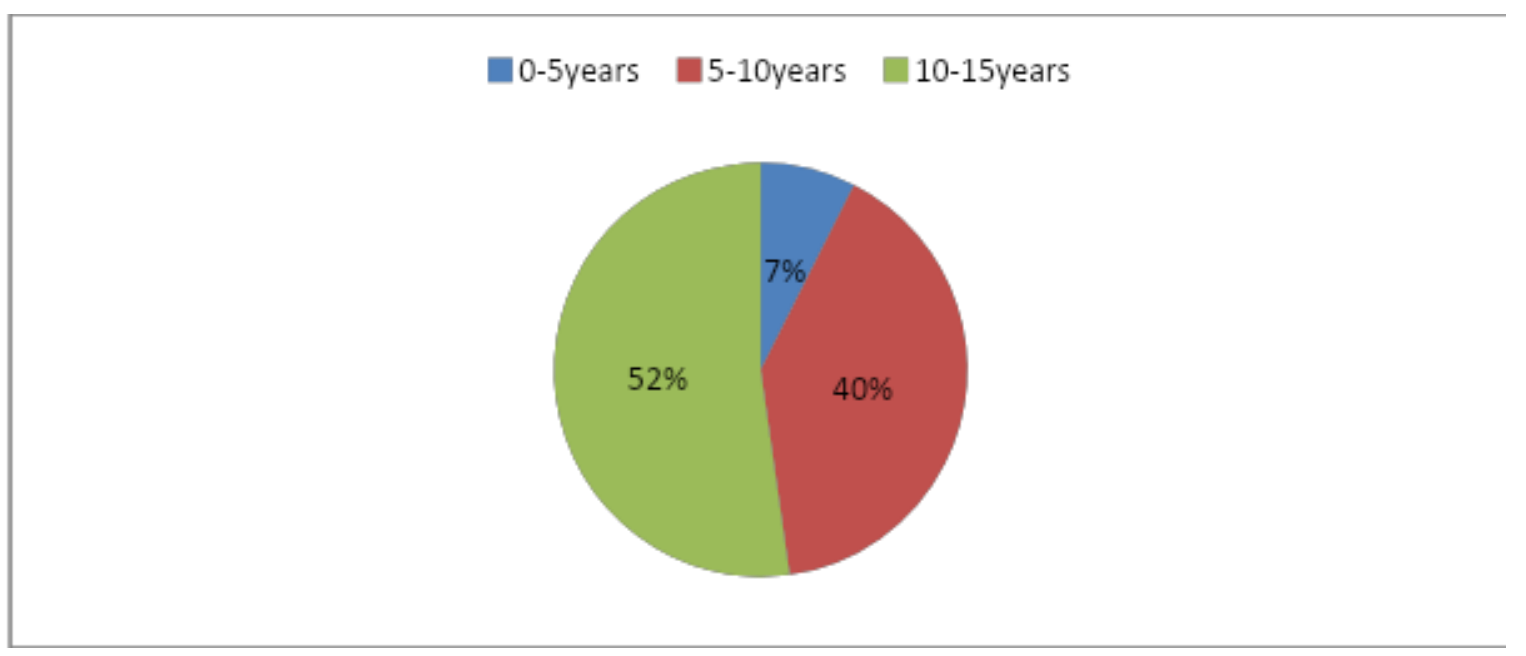

Chart-2

Gender issuance (N-67;Male-41[61.19\%]:Female-26[38.81\%])

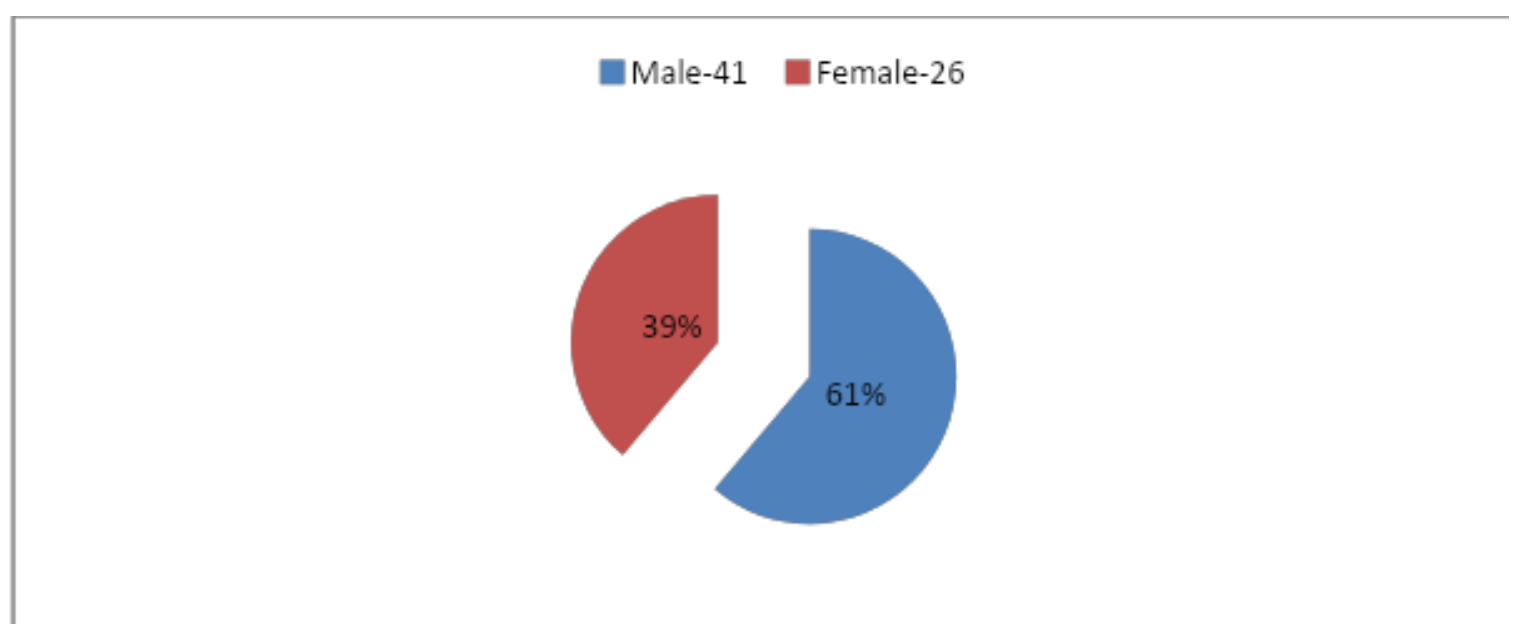

CHART-3

Presenting aspect $\left(\mathrm{N}-67 ; 1^{\text {st }}\right.$ group-Rhinitis, nasal discharge-46[68.66\%]: $2^{\text {nd }}$ group-Rhinitis, nasal discharge, nasal congestion13[19.40\%]: $3^{\text {rd }}$ group-Rhinitis, nasal discharge, nasal blockage, Mouth breathing-8[11.94\%]) 


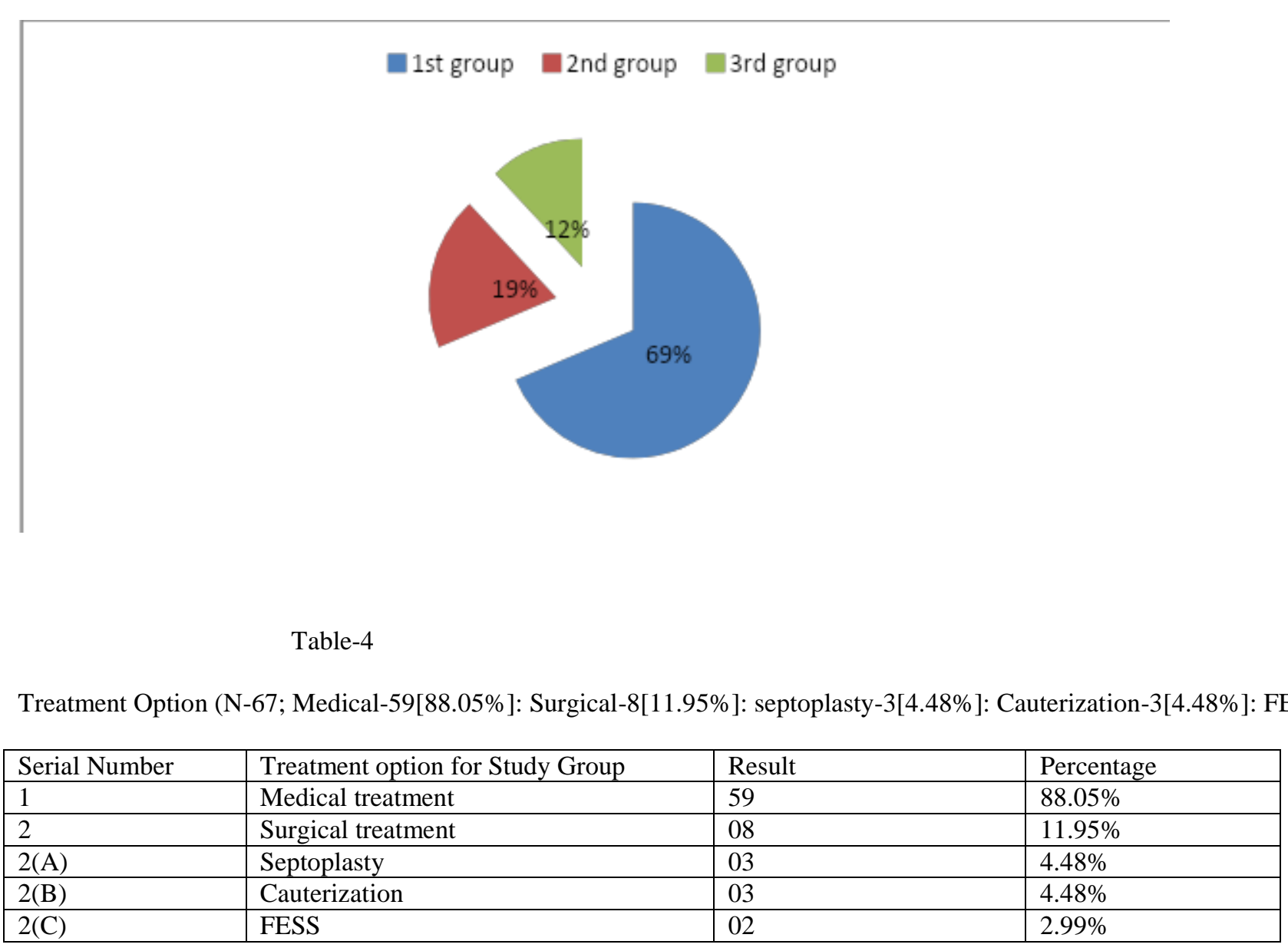

\section{Discussion:}

The parent are always want to do the best wellbeing for their children without any relation with literacy in anywhere of the world. According to UNESCO an adult literacy rate of Bangladesh is $72.89 \%$. So many of parent weren't aware of the specific milestone of their children with age after birth whereas the children's facial growth $60 \%$ completed by the age of 8 years and $90 \%$ completed by the age of 12 years. If there is any retardation of growth and development it must be evaluated properly. Facial growth and development is one of the most important factors for children which was impaired due to ADS and DNS. Some unlettered mother believed that father is snoring and mouth breathing at night during sleeping, the child was inherited it from his father which is superstition in this class of people or social myth. Some educated parent even physician parent also knew that their child was suffering from ADS but they were continuing the medical treatment for long time just which was suppressing the aggravating factors however surgery is the only curable option of ADS. The time killing to take decision for surgical treatment was one of the commonest cause for persisting impacts of ADS on nasal septum after adenoidectomy. Our case study also suggested that the percentage of age allocation were highest in 10-15 years age of children (52.24\%). ADS are higher frequency in children with allergic rhinitis, most common allergen is house dust, other is cigarette smoke exposure and allergic rhinitis. Pollen is the commonest cause of seasonal allergic rhinitis in Bangladesh. There are six different seasonal variations like spring, autumn, late autumn, summer, cold and rainy seasons in a year in which various plants release tiny pollen grains for fertilization. There were very few study work about persistence impact of ADS after adenoidectomy on nasal septum or craniofacial growth impairment in children with DNS. ${ }^{12}$ Incidence of persistence impact of ADS on nasal septum after adenoidectomy were variable in different study due to these were only on pediatric cohort study. In our study, three different stages we were calculate the incidence like in outpatient department, in inpatient routine operative patient and in inpatient adenoidectomy children. These were accordingly $0.06 \%, 2.44 \%$ and $20.87 \%$ whereas Abreu RRD et al series showed only in mouth breathing children due to ADS were $23.7 \%$ on the basis of endoscopic findings which is near to our study. ${ }^{13}$ Age allocated the number of most children were 10-15 years in which facial development completed by $90 \%$ and the parent had no other alternative except surgery after long time suffering from ADS and it complications which were supported by Tankel JW 
series of study. ${ }^{14}$ In case of Gender issuance male were predominant in our study which were supported by EH Huizing series. ${ }^{15}$ In Bangladesh more than $80 \%$ are Muslim, male are going out home for working and other purpose than female and male children were exposed to the dust and environmental pollution more. The presenting aspects were suggestive of allergic rhinitis of almost all our cases which were supported by Borges WG series. ${ }^{16}$ The DNS were second most impacts of adenoids in our study which were treated by septoplasty were also supported by Sullivan S series. ${ }^{17}$ HIT were sequence of ADS and DNS which were treated by surgical intervention for reduction consecutive various methods which were supported by Hol MKS series ${ }^{18}$ where they were practicing it by inferior turbinoplasty but we were did it by surface cauterization. FESS were done in 2 of our children which also supported by Lazar RH et al series. ${ }^{19}$ There were some study to do the adenoidectomy with septoplasty or turbinoplasty as a same setting which may causes more complications whereas we did it separate entity. ${ }^{20}$ It was difficult to both of our lettered and unlettered parent to understanding the necessity to achieve the one operation like adenoidectomy whereas they were strongly refused more than one operation in a same assignment.

Conclusion:

A child should be a beautiful smile, pleasing face and a normal and functional bite which are heart full desire for all of our parents. So adenoidectomy should be done as early as possible before develop the craniofacial growth impairment and produces the ear or nasal complications. If it is linger for a prolonged time, the children developed craniofacial abnormalities and as a consequence DNS and HIT. So after adenoidectomy nasal obstruction continued due to DNS or HIT which will need second surgical intervention. Some surgeons practiced to do more than one operation at a time but most of surgeons and almost all parents didn't agree to accomplish more than one operation at a time. It may make more troublesome for the children, parents and surgeon. It may increase the rate of complications, morbidity and mortality. It is more important that before selection of surgery and also patient, details counseling with the parents that if the Allergic Rhinitis, DNS and HIT present with adenoids and after adenoidectomy Allergic Rhinitis, DNS and HIT produce symptom these should must be corrected by medical or repeated surgery in a second setting.

Reference:

1. Jaw TS, Shew RS, Liu GC, Lin WC. Development of Adenoids: a study by measurement with MRI images. Kaobsiung J Med Sci 1999; 15: 12-18.

2. Vogler RC, Ii FJ,Pilgram TK. Age-Specific size of the normal adenoid pad on magnetic resonance imaging. Clin Otol Allied Sci 2000;25:392-5.

3. Wysocka J, Hassman E, Lipska A, Musiatowicz M. Naïve and memory T-cells in hypertrophied adenoids in children according to age. Int J Pediator Otolaryngol 2003; 67:231-41.

4. Brandtzaeg P. Immunology of the tonsils and adenoids: everything the ENT surgeon needs to know. Int $\mathrm{J}$ Pediatr Otorhinolaryngol 2003; 67:69-76.

5. Modrzynski M, Zawisza E, Rapiejko P. Serum immunoglobulin E levels in relation to waldeyer's ring surgery. PrzegiLekarsk 2003;60:325-8.

6. Shintani T, Asakura K, Kataura A. 1997 Evaluation of the role of adenotonsillar hypertrophy and facial morphology in children with obstructive sleep apnea. Journal for Oto-Rhino-Laryngology and its Related Specialistics 59:286-291.

7. Solow B, Kreiborg S. 1977. Soft tissue stretching: a possible control factor in craniofacial morphogenesis. Scandinavian Journal of Dental Research. 85: 505-507.

8. Linder-Aronson S, Woodside DG, Lundstrom A. 1986. Mandibular growth direction following adenoidectomy. American Journal of Orthodontics. 89: 273-284.

9. B. Q. Souki, G. B. Pimenta, M. Q. Souki, LP. Franco, H. M> Becker, J. A. Pinto. Prevalence of malocclusion among mouth breathing children: do expectations meet reality? Int J Pediator Otorhinolaryngol 73(5)(2009) 767-773.

10. D. Bresolin, P. A. Shapiro, G. G. Shapiro, M. K. Chapko, S. Dassel. Mouth breathing in allergic children: its relationship to dentofacial development. Am J Orthod 83(4) (1983) 334-340.

11. R. Risavi, Z. Pisl, N. Sperm, I. Klapan. Rhinomanometrical findings after Septoplasty in Children. Int J Pediator Otorhinolaryngol. 16(2)(1988) 149-155.

12. D’Ascanio L, Lancione C, Pompa G, Rebuffini E, Mansi N, Manzini M. A Cephalometric Comparative Study. Int J of Pediatric Otorhinolaryngology 74(2010) 1180-1183.

13. Abreu RR, Rocha RR, Lamounier JA, Guerra AFM. Etiology,Clinical Manifestations and concurrent findings in mouth breathing Children. Journal de Pediatria-Vol.84 No.6.2008:529535.

www.scirj.org

(C) 2020, Scientific Research Journal

http://dx.doi.org/10.31364/SCIRJ/v8.i3.2020.P0320751 
14. Tankel JN, Cheesman AD. "Symptom relief by Adenoidectomy and relationship to adenoid and post-nasal airway size." J laryngol Otol 1986;100(6):637-40.

15. EH Huizing, J.A.M. De Groot. Functional Reconstructive Surgery, Thieme, Stuttgart, New York, 2003.

16. Borges WA, Burns DA, Felizola ML, Oliveira BA, Hamu CS, Freitas VC. Prevalence of allergic rhinitis among adolescents from Distrito Federai, Brazil: Comparison between ISAAC phases 1 and 3. J Pediator (Rio J). 2006;82:137-43.

17. Sullivan S, Lik, Guilleminault C. Nasal Obstruction in Children with Sleep -disordered Breathing. Ann Acad Med Singapore 2004; Aug 37(8):645-8.

18. Hol MKS, Hiuzing EH. Treatment of inferior turbinate pathology: a review and critical evaluation of the different techniques. Rhinology 2000;38:157-66.

19. Lazar RH, Younis RT. Functional Endonasal Sinus Surgery in the Pediatric Age Group. In:Advances in Oto Laryngology Year Book (Vol Four), C. V. Mosby co. pp. 1-14,1990.

20. Langille M, EL-Hakim H. Pediatric inferior turbinoplasty with or without adenoidectomy: Preliminary report an improvement of quality of life, Symptom, control and safety. J Otolaryngol Head Neck Surg 2011; Oct: 40(5):420-6. 